\title{
Acta Iguazu
}

ISSN: 2316-4093

\section{Produtividade e qualidade da parte aérea da mandioca em função da época de poda e colheita}

\author{
Elizeu da Silva Martins ${ }^{1}$, Eliete de Fátima Ferreira da Rosa ${ }^{2}$, Jéssica Fernandes Kaseker ${ }^{3 *}$, \\ Marcos André Nohatto ${ }^{2}$, Miguelangelo Ziegler Arboitte², Samuel Freguglia Bereta ${ }^{2}$ \\ ${ }^{1}$ Serviço Nacional de Aprendizagem Rural (SENAR), São Martinho da Serra - RS \\ ${ }^{2}$ Instituto Federal Catarinense (IFC), Santa Rosa do Sul - SC \\ ${ }^{3}$ Pesquisador Autônomo, Itaipulândia - PR \\ *Autor para correspondência: jessikaseker@hotmail.com \\ Artigo enviado em 08/01/2020, aceito em 03/03/2021.
}

\begin{abstract}
Resumo: 0 uso das raízes da mandioca é bastante amplo. Já a parte aérea, que acaba sendo desperdiçada, pode representar uma alternativa de fonte alimentar aos animais. Diante disso, o objetivo do presente trabalho foi avaliar a qualidade bromatológica da parte aérea da mandioca em diferentes épocas de poda e de colheita, e sua influência na produtividade de raízes da cultivar Olho Junto. 0 delineamento experimental foi de blocos casualizados com quatro repetições e quatro tratamentos, que consistiram em diferentes épocas de poda e colheita, sendo eles: poda no período vegetativo e colheita no período de repouso fisiológico; poda e colheita no período de repouso fisiológico; poda no período de repouso fisiológico e colheita no período vegetativo antecipado; poda no período de repouso fisiológico e colheita no final do período vegetativo. 0 tratamento com poda no período vegetativo apresentou menor produtividade de amido, mas não houve efeito na produtividade de raízes tuberosas, teor de amido e de matéria seca. A parte aérea podada no mesmo período apresentou maior produtividade de massa verde, teor de proteína bruta, nutrientes digestíveis totais e menor teor de fibras, tanto na forragem verde quanto ensilada, devido a maior relação folha/caule das plantas. A colheita durante o período vegetativo resultou em maior teor de massa seca na parte aérea, proteína bruta e fibra em detergente neutro. A parte aérea da mandioca é uma opção viável para a utilização na alimentação animal, com qualidade adequada nas condições avaliadas.
\end{abstract}

Palavras-chave: análise bromatológica, Manihot esculenta Crantz, raízes, silagem

\section{Yield and quality of cassava shoot according to the pruning and harvest season}

Abstract: The use of cassava roots is quite wide. The aerial part, which ends up being wasted, may represent an alternative source of food for animals. Therefore, the objective of the present study was to evaluate the bromatological quality of cassava shoot at different pruning and harvest season, and its influence on the root productivity of the cultivar Olho Junto. The experimental design was randomized blocks with four replications and four treatments, which consisted of different pruning and harvest season: pruning in the vegetative period and harvest in the physiological rest period; pruning and harvesting during the physiological rest period; pruning in the physiological rest period and harvest in the early vegetative period; pruning in the physiological rest period and harvest in the late vegetative period. The pruning treatment during the growing season showed lower starch productivity, but there was no effect on tuberous root productivity, starch content and dry matter. The pruned aerial part in the same period showed higher green mass productivity, crude protein content, total digestible nutrients and lower fiber content, both in green and ensiled forage, due to the higher leaf 
/stem ratio of the plants. The harvest during the growing season resulted in higher dry matter content in the shoot, crude protein and neutral detergent fiber. The cassava shoot is a viable option for use in animal feed, with adequate quality in the conditions evaluated.

Keywords: bromatological analysis, Manihot esculenta Crantz, roots, silage

\section{Introdução}

0 cultivo da mandioca (Manihot esculenta Crantz) ocorre em todo o território brasileiro, com produção aproximada de 17,6 milhões de toneladas em 2018. Em Santa Catarina a produção está em torno de 350 mil toneladas, com produtividade média de 19,24 tha-1 (IBGE, 2019). No Extremo Sul Catarinense a cultura da mandioca assume papel de destaque como uma das mais cultivadas, sendo fonte de renda e emprego na agricultura familiar. Nessa região, é bastante difundido o uso da cultivar Olho Junto, devido a sua boa adaptação e produtividade.

A mandioca se adapta a solos com baixa fertilidade e condições climáticas desfavoráveis a outras culturas (Ferreira et al., 2009). É uma planta com grande potencial para alimentação humana e animal. Suas raízes servem de fonte para produção industrial de fécula e farinha, além do consumo in natura. Já a parte aérea é um subproduto pouco aproveitado, mas que tem potencial nutritivo para ser aproveitada para alimentação animal, reduzindo os custos na produção e aumentando a lucratividade (Marques et al., 2013; Fernandes et al., 2016). A parte aérea da mandioca para indústria possui altos teores de ácido cianídrico, que pode ser tóxico, porém a exposição da planta ao sol após o corte reduz os teores do composto à níveis seguros para a alimentação animal (Fernandes et al., 2016).

A parte aérea pode ser fornecida aos animais na forma de forragem fresca e na forma de silagem, processo que também atua na redução dos teores de ácido cianídrico, ambos apresentando valores bromatológicos e nutricionais adequados para a alimentação animal, (Azevedo et al., 2006; Ferreira et al., 2009; Silva et al., 2010). Entretanto, fatores como a variedade e/ou cultivar, época de poda e de coleta dos materiais podem alterar a composição química da parte aérea e devem ser considerados (Silva et al., 2010; Souza et al., 2011; Marques et al., 2013).

0 aproveitamento da parte aérea ocorre tanto na colheita como após a realização de poda em cultivos bianuais, considerando que apenas parte das plantas são utilizadas como manivassemente para posterior plantio. Entretanto, é fundamental garantir que essa prática não prejudique a produção da lavoura. Alguns estudos mostram que a poda não interfere na produção de farinha e nos teores de matéria seca e amido (Oliveira et al., 2010; Moreira et al., 2014), enquanto outros autores relatam que quando a poda é realizada no período vegetativo da planta a produção de raízes é reduzida, devido ao consumo de reservas das raízes para a recuperação da parte aérea retirada e desenvolvimento das brotações, sendo recomendo realizar a poda no período de repouso fisiológico (Andrade et al., 2011; Moreira et al., 2017). No experimento realizado por Oliveira et al. (2010) a colheita da mandioca aos 30, 60, 90,120 , 150 e 180 dias após a poda afetou a produção de raízes, em comparação com plantas não podadas. Assim, é importante verificar o momento ideal da poda para não reduzir a produtividade de raízes. Na literatura existe carência de resultados de pesquisa com colheitas acima de 180 dias após a poda, porém 
esta condição poderia ser interessante para o cultivo, uma vez que a planta teria maior tempo para a rebrota $\mathrm{e}$ desenvolvimento.

Além da época de realização da poda, o intervalo entre esta e a colheita pode alterar a produtividade das raízes. 0 período de colheita das raízes ocorre entre 6 a 24 meses após o plantio, dependendo da cultivar e da demanda do mercado, sendo que na região do Extremo Sul Catarinense a colheita ocorre entre 9 a 21 meses após o plantio, geralmente efetuada no período de repouso fisiológico da planta, que é o período que garante maior produção de raízes (Andrade et al., 2011).

Diante do exposto, a hipótese adotada é de que a parte aérea da mandioca possui composição adequada para a alimentação animal, e a realização de poda não traz prejuízos para o desenvolvimento radicular. Assim, o presente estudo tem como objetivo avaliar a produtividade e a qualidade bromatológica da parte aérea da mandioca, fresca e após silagem, em diferentes épocas de poda e de colheita, bem como a influência da poda na produtividade de raízes da cultivar "Olho Junto".

\section{Material e métodos}

0 experimento foi conduzido no município de Sombrio, SC $\left(29^{\circ} 03^{\prime} 44^{\prime \prime S}\right.$ $49^{\circ} 38^{\prime} 32^{\prime \prime W}$ ), no período de outubro de 2016 a junho de 2018. 0 clima da região é do tipo Cfa, com temperatura média de $19^{\circ} \mathrm{C}$ e chuvas bem distribuídas, com precipitação anual média de $1600 \mathrm{~mm}$. A precipitação e temperatura diárias durante o período de condução do experimento são apresentados na Figura 1.

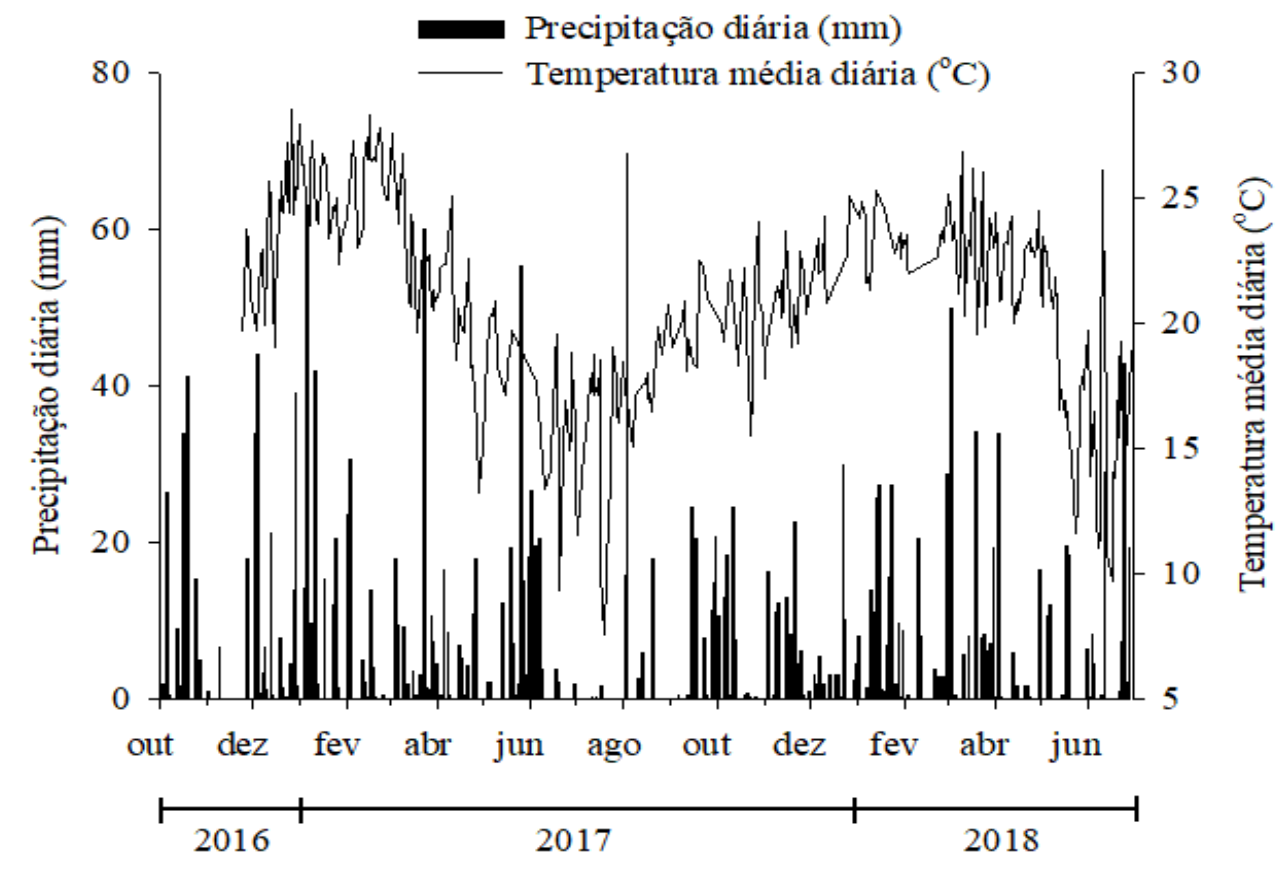

Figura 1. Valores diários de precipitação e temperatura média registrados durante o período de condução do experimento (período de 10/2016 a 07/2018) na estação experimental da EPAGRI.

O solo na área experimental foi classificado como NEOSSOLO QUARTZARÊNICO, e apresentava as seguintes características químicas na camada de 0-0,2 m: pH em água 6,2; $10 \mathrm{~g}$ $\mathrm{kg}^{-1}$ de matéria orgânica; $100 \mathrm{~g} \mathrm{~kg}^{-1}$ de 
argila; 85,0 $\mathrm{mg} \mathrm{dm}^{-3}$ de $\mathrm{P}\left(\right.$ Mehlich $\left.^{-1}\right)$; 78,0 $\mathrm{mg} \mathrm{dm}^{-3}$ de $\mathrm{K}\left(\right.$ Mehlich $\left.^{-1}\right) ; 0$ cmol $_{\mathrm{C}}$

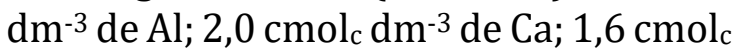
$\mathrm{dm}^{-3}$ de $\mathrm{Mg} ; 3,62 \mathrm{cmol}_{\mathrm{c}} \mathrm{dm}^{-3} \mathrm{de}$ capacidade de troca de cátions (CTC); 69\% de saturação de bases (V\%).

Foram utilizadas manivas-semente da cultivar "Olho Junto", adquiridas de produtores locais, com 0,10 a $0,12 \mathrm{~m}$ de comprimento. 0 plantio ocorreu no dia 30 de outubro de 2016, em profundidade de 0,05 a $0,10 \mathrm{~m}$. Previamente a instalação do experimento foi realizado o revolvimento do solo e a aplicação de 700 $\mathrm{kg} \mathrm{ha}^{-1}$ de gesso agrícola, para elevar os teores de cálcio.
0 delineamento experimental foi em blocos casualizados, com quatro repetições e quatro tratamentos, que consistiram na combinação de diferentes épocas de poda e colheita, sendo: poda no período vegetativo e colheita no período de repouso fisiológico (PVegCRep) ; poda e colheita no período de repouso fisiológico (PRepCRep); poda no período de repouso fisiológico e colheita no período vegetativo antecipado (PRepCVegA); poda no período de repouso fisiológico e colheita no final do período vegetativo (PRepCVeg). Os tratamentos são descritos detalhadamente na Tabela 1.

Tabela 1. Descrição dos tratamentos com base na época de poda da parte aérea e colheita das plantas de mandioca, cultivar Olho Junto, no ano agrícola de 2017 e 2018.

\begin{tabular}{ccccc}
\hline \multirow{2}{*}{ Tratamentos } & \multicolumn{2}{c}{ Poda } & \multicolumn{2}{c}{ Colheita } \\
\cline { 2 - 5 } & Época & $\begin{array}{c}\text { Meses após } \\
\text { plantio }\end{array}$ & Época & $\begin{array}{c}\text { Meses após } \\
\text { plantio }\end{array}$ \\
\hline PVegCRep & Abril/2017 & 7 & Junho/2018 & 20 \\
PRepCRep & Julho/2017 & 10 & Junho/2018 & 20 \\
PRepCVegA & Julho/2017 & 10 & Março/2018 & 17 \\
PRepCVeg & Julho/2017 & 10 & Abril/2018 & 18 \\
\hline
\end{tabular}

Cada parcela foi composta por quatro linhas de 25 plantas, dispostas num espaçamento de $0,8 \mathrm{~m}$ entre plantas e $0,8 \mathrm{~m}$ entrelinhas, visando população de 15.625 plantas ha-1, totalizando $64 \mathrm{~m}^{2}$. As cinco primeiras plantas de cada extremidade da linha serviram como bordadura, sendo considerada parcela útil apenas as quinze plantas centrais para as avaliações.

A adubação foi realizada de acordo com o recomendado pela interpretação da análise de solo (CQFS, 2016), sendo feita somente no primeiro ano, onde foram aplicados $150 \mathrm{~kg} \mathrm{ha}^{-1}$ do adubo formulado N-P-K 4-20-20 juntamente com $370 \mathrm{~kg} \mathrm{ha}^{-1}$ de sulfato de amônio, parcelados aos 45 e 75 dias após o plantio. 0 controle de plantas daninhas foi realizado por meio da capina logo após o estabelecimento da cultura (dezembro/2016 e janeiro/2017), no começo da brotação do segundo ciclo (setembro 2017) e no estabelecimento do segundo ciclo (dezembro/2017 e janeiro/2018). Foram ainda realizadas três pulverizações de calda bordalesa (maio/2017), com intervalo de sete dias entre as aplicações, para controle da antracnose (Colletrotrichum gloeosporioides), e três pulverizações do inseticida Imidacloprido (Evidence 700 $W^{\circledR}{ }^{\circledR}$ ) nos dois anos de condução do experimento (dezembro/janeiro), com 15 dias de intervalo entre as aplicações, para controle da mosca-do-broto (Neosilba perezi). Todas as pulverizações foram realizadas com pulverizador costal.

As podas foram realizadas através do corte da parte aérea, a $0,15 \mathrm{~m}$ do solo, na época determinada para cada tratamento. A colheita ocorreu entre março e junho de 2018, de acordo com 
cada tratamento, sendo coletadas as raízes e a parte aérea. As partes aéreas coletadas na poda e na colheita foram submetidas aos mesmos procedimentos.

Após a coleta, as partes aéreas de todas as plantas da área útil da parcela foram conjuntamente trituradas, em motor estacionário, e a massa resultante pesada para a determinação da massa verde em $t$ ha $^{-1}$. Em seguida, retirou-se uma amostra homogeneizada de 0,5 kg do material triturado, para avaliação da qualidade bromatológica da forragem fresca. 0 restante da massa foi destinado ao processo de ensilagem, em silos de laboratório do tipo Bunsen com capacidade de $0,0043 \mathrm{~m}^{3}$ e densidade de $650 \mathrm{~kg} \mathrm{~m}^{-3}$. Após 60 dias de fermentação, os tubos foram abertos para retirada de uma amostra.

A análise das amostras de forragem fresca e de silagem foram feitas da mesma forma. As amostras foram secas em estufa de ar forçado a $65^{\circ} \mathrm{C}$, até atingir peso constante, e posteriormente pesadas para determinação da matéria parcialmente seca (\% MS). Em seguida, as amostras foram trituradas em moinho tipo Willey com peneiras de $1 \mathrm{~mm}$ e levadas ao laboratório para análise bromatológica.

0 teor de proteína bruta (PB), em porcentagem, foi determinado de acordo com o método micro Kjeldahl (Silva e Queiroz, 2002). A porcentagem dos componentes da matéria seca (MS), fibra em detergente neutro (FDN) e fibra em detergente ácido (FDA), foram determinados utilizando a metodologia descrita por Senger et al. (2008). Os nutrientes digestíveis totais (NDT), em porcentagem, foram calculados por meio da equação: NDT= 99,39-(0,741*FDN), onde FDN é a porcentagem de fibra em detergente neutro (Cappelle et al., 2001).

Foi realizada a determinação de produtividade de raízes tuberosas (PRT) através da pesagem das raízes de todas as plantas da área útil da parcela, seguida da estimativa para toneladas por hectare. A massa de $3 \mathrm{~kg}$ de mandioca fresca em água foi determinada por meio do teste da balança hidrostática (Oliveira et al., 2011), sendo este valor utilizado para calcular a porcentagem de massa seca (MS) através da equação: MS $=15,75+$ $0,0564 X$, onde $X$ é a massa de $3 \mathrm{~kg}$ de mandioca fresca em água. Em seguida foi calculado o teor de amido (TA), em porcentagem, através da equação: $\mathrm{TA}=$ MS - 4,65, onde MS é a massa seca (\%). Foi ainda calculada a produtividade de amido (PA), em toneladas por hectare $(\mathrm{t}$ ha $^{-1}$ ) através da equação: PA $=$ PRT $^{*}$ TA, onde PRT é a produtividade de raízes tuberosas ( $\mathrm{t} \mathrm{ha}{ }^{-1}$ ) e TA é o teor de amido (\%).

Os dados foram submetidos à análise de variância $(\mathrm{p}<0,05)$ e posteriormente ao teste de comparação de médias (Tukey $\mathrm{p}<0,05$ ) utilizando o programa estatístico SISVAR.

\section{Resultados e discussão}

Os tratamentos não diferiram significativamente quanto à produtividade de raízes tuberosas, teor de amido e de matéria seca, porém as diferenças nos valores absolutos dessas variáveis, quando multiplicadas, resultaram em alteração na produtividade de amido (Tabela 2). Embora o maior tempo de permanência das plantas no campo possa gerar maior acúmulo de reservas e consequentemente aumentar a produtividade de raízes tuberosas (Oliveira et al., 2010; Lessa et al., 2019), não houve diferença entre os tratamentos (Tabela 2), indicando que o período de três meses entre o tratamento colhido mais cedo e o mais tardio não foi suficiente para demonstrar esse efeito. A produtividade obtida foi alta, bastante superior à média do Estado de 19,24 tha1 (IBGE, 2019), sendo assim é possível realizar a colheita tanto aos 17 quanto 
aos 20 meses após o plantio sem prejuízos para a cultura. Os valores relatados na literatura são bastante variáveis, uma vez que a característica é influenciada pela cultivar, clima, época de colheita, e manejo de adubação (Oliveira et al., 2017; Lessa et al., 2019).

A produtividade de amido foi superior no tratamento podado e colhido no período de repouso fisiológico (PRepCRep) em relação ao tratamento podado durante o período vegetativo
(PVegCRep) e colhido antecipadamente (PRepCVegA), possivelmente devido a época de poda ter proporcionado a diminuição do consumo dos carboidratos de reserva, e a colheita mais tardia resultou em maior tempo para o acúmulo (Lessa et al., 2019). No trabalho de Moreira et al. (2014) a produtividade de amido aumentou cerca de $2 \mathrm{t} \mathrm{ha}^{-1}$ quando o intervalo entre podas passou de quatro para seis meses, resultando em maior distância entre a última poda e a colheita.

Tabela 2. Parâmetros produtivos de raízes de mandioca da cultivar Olho Junto coletadas em diferentes épocas, sendo: $\mathrm{PRT}=$ produtividade de raízes tuberosas em toneladas por hectare; $\mathrm{PA}=$ produtividade de amido em toneladas por hectare; $\mathrm{TA}=$ teor de amido em porcentagem; $\mathrm{MS}=$ matéria seca em porcentagem

\begin{tabular}{lcccc} 
Tratamentos & PRT & PA & TA & MS \\
\hline PVegCRep & $43,80^{\mathrm{ns}}$ & $13,31 \mathrm{~b}$ & $30,39 \mathrm{~ns}$ & $35,04 \mathrm{~ns}$ \\
PRepCRep & 55,49 & $17,31 \mathrm{a}$ & 31,19 & 35,84 \\
PRepCVegA & 47,21 & $13,60 \mathrm{~b}$ & 28,80 & 33,44 \\
PRepCVeg & 52,76 & $15,36 \mathrm{ab}$ & 29,12 & 33,77 \\
\hline Média geral & 49,82 & 14,89 & 29,88 & 34,52 \\
\hline$p$-value & 0,1237 & 0,0208 & 0,1051 & 0,1078 \\
CV $(\%)$ & 13,37 & 10,73 & 4,54 & 3,93 \\
\hline
\end{tabular}

ns: Não significativo $(\mathrm{p}<0,05) .{ }^{*}$ Médias seguidas de mesma letra na coluna não diferem pelo teste de Tukey $(\mathrm{p}<0,05)$. PVegCRep: poda no período vegetativo e colheita no período de repouso fisiológico; PRepCRep: poda e colheita no período de repouso fisiológico; PRepCVegA: poda no período de repouso fisiológico e colheita no período vegetativo antecipado; PRepCVeg: poda no período de repouso fisiológico e colheita no final do período vegetativo.

0 teor de amido e a porcentagem de matéria seca não diferiram entre os tratamentos, e os valores médios estão de acordo com os relatados na literatura e considerados satisfatórios para a indústria (Oliveira et al., 2010; Moreira et al., 2014), indicando que as diferentes épocas de poda e de colheita não prejudicaram a qualidade do produto. No estudo desenvolvido por Andrade et al. (2011), comparando 12 épocas de poda, foi observado que na média dos tratamentos podados houve redução da massa seca e do teor de amido em comparação com a testemunha sem poda, de 32,7 para $31,5 \%$ e de 28,1 para 26,9\%, respectivamente. Entretanto, quando se comparam as épocas de poda, os autores ressaltam que as plantas podadas durante o repouso fisiológico têm mais raízes e com maior teor de matéria seca.

Os resultados oriundos da poda da parte aérea diferiram em quase todas as variáveis analisadas (Tabela 3). A produtividade da massa verde (PMV) variou de 11,66 a 20,33 $\mathrm{t} \mathrm{ha}^{-1}$. 0 maior rendimento foi constatado no tratamento com a poda durante o período vegetativo (PVegCRep), no mês de abril. Isso se deve às ramas nesse período possuírem grande quantidade de folhas e pecíolos, diferentemente dos outros tratamentos que ocorreram na fase de repouso da planta. 
Não houve diferença na porcentagem de massa seca entre os tratamentos, já os demais atributos bromatológicos da parte aérea diferiram de acordo com a época de poda (Tabela 3), apresentando o mesmo comportamento na forragem fresca e após a silagem. 0 tratamento podado durante $o$ período vegetativo (PVegCRep) obteve o maior percentual de proteína bruta em relação aos demais meses, o que condiz com o fato de serem brotações mais nova e com maior quantidade de folhas (Moreira et al., 2017). Em contrapartida, os teores de fibra (FDA e FDN), que são maiores em brotações mais desenvolvidas em função da deposição de lignina nos caules, foi também menor nesse tratamento. A maior relação folha/caule também resultou em maiores teores de nutrientes digestíveis totais.

Tabela 3. Produtividade da massa verde (PMV), matéria seca (MS), proteína bruta (PB), fibra em detergente neutro (FDN), fibra em detergente ácido (FDA) e nutrientes digestíveis totais (NDT) da poda da parte aérea da mandioca na forma de forragem fresca e de silagem.

\begin{tabular}{|c|c|c|c|c|c|c|}
\hline \multirow[t]{2}{*}{ Tratamentos } & PMV & MS & PB & FDN & FDA & NDT \\
\hline & tha-1 & $\%$ & \multicolumn{4}{|c|}{$\%$ na MS } \\
\hline & \multicolumn{6}{|c|}{ Forragem Fresca } \\
\hline PVegCRep & $20,33 a$ & $20,85^{\mathrm{ns}}$ & $13,81 \mathrm{a}$ & $32,55 b$ & $23,76 b$ & $74,52 \mathrm{a}$ \\
\hline PRepCRep & $11,66 b$ & 20,23 & $8,70 \mathrm{~b}$ & $44,08 \mathrm{a}$ & $27,78 a$ & $65,70 \mathrm{~b}$ \\
\hline PRepCVegA & $12,42 b$ & 20,29 & $8,93 b$ & $46,14 a$ & $25,68 a b$ & $64,13 b$ \\
\hline PRepCVeg & $13,02 b$ & 20,34 & $8,88 b$ & $33,92 b$ & $27,50 \mathrm{a}$ & $73,47 a$ \\
\hline Média & 14,36 & 20,43 & 10,08 & 39,17 & 26,18 & 69,46 \\
\hline p-value & 0,0921 & 0,5455 & 0,0030 & 0,0001 & 0,001 & 0,002 \\
\hline \multirow[t]{2}{*}{ CV (\%) } & 20,88 & 3,21 & 15,46 & 6,02 & 4,02 & 2,59 \\
\hline & \multicolumn{6}{|c|}{ Silagem } \\
\hline PVegCRep & - & $23,58^{\text {ns }}$ & $11,04 a$ & $28,02 b$ & $21,76 b$ & $77,98 \mathrm{a}$ \\
\hline PRepCRep & - & 23,81 & $8,22 b$ & $39,02 a$ & $27,17 \mathrm{a}$ & $69,57 b$ \\
\hline PRepCVegA & - & 23,93 & $8,40 \mathrm{~b}$ & $39,37 a$ & $26,97 a$ & $69,37 b$ \\
\hline PRepCVeg & - & 23,91 & $8,64 \mathrm{~b}$ & $38,59 a$ & $27,54 a$ & $69,90 \mathrm{~b}$ \\
\hline Média & - & 23,81 & 9,08 & 36,25 & 25,86 & 71,69 \\
\hline$p$-value & & 0,9781 & 0,003 & 0,0001 & 0,0002 & 0,0002 \\
\hline CV (\%) & - & 5,34 & 9,45 & 3,52 & 3,36 & 1,36 \\
\hline
\end{tabular}

ns: Não significativo $(\mathrm{p}<0,05)$. ${ }^{*}$ Médias seguidas de mesma letra na coluna não diferem pelo teste de Tukey $(\mathrm{p}<0,05)$. PVegCRep: poda no período vegetativo e colheita no período de repouso fisiológico; PRepCRep: poda e colheita no período de repouso fisiológico; PRepCVegA: poda no período de repouso fisiológico e colheita no período vegetativo antecipado; PRepCVeg: poda no período de repouso fisiológico e colheita no final do período vegetativo.

A fração FDN possui em sua composição estruturas pouco ou não digeríveis como a lignina, que influenciam negativamente na fração NDT (Cappelle et al., 2001; Moreira et al., 2017), o que foi ser observado nos 
tratamentos com poda no período vegetativo e colheita no período de repouso fisiológico (PVegCRep) e com poda no período de repouso fisiológico e colheita no final do período vegetativo (PRepCVeg) que apresentaram menores valores de FDN e maiores valores de NDT (Tabela 3). A ingestão de volumosos por ruminantes pode ser limitada em forragens com mais de 55 a $60 \%$ de FDN, devido ao efeito de repleção ruminal (Pereira et al., 2010). Em todos os tratamentos os valores observados estão abaixo desse limite, sendo adequado para o uso neste quesito.

Tabela 4. Produtividade da massa verde (PMV), matéria seca (MS), proteína bruta (PB), fibra em detergente neutro (FDN), fibra em detergente ácido (FDA) e nutrientes digestíveis totais (NDT) da parte aérea da mandioca na época da colheita, na forma de forragem fresca e de silagem.

\begin{tabular}{|c|c|c|c|c|c|c|}
\hline \multirow{2}{*}{ Tratamentos } & PMV & MS & PB & FDN & FDA & NDT \\
\hline & tha-1 & $\%$ & \multicolumn{4}{|c|}{$\%$ na MS } \\
\hline & \multicolumn{6}{|c|}{ Forragem Fresca } \\
\hline PVegCRep & $12,00 \mathrm{~b}$ & $25,13 a$ & $6,90 \mathrm{~b}$ & $30,43 b$ & $24,14 a$ & $76,14 a$ \\
\hline PRepCRep & $20,34 \mathrm{ab}$ & $25,10 \mathrm{a}$ & $7,03 b$ & $32,86 a b$ & $22,64 a$ & $74,28 \mathrm{ab}$ \\
\hline PRepCVegA & $22,52 a$ & $21,62 b$ & $11,46 a$ & $38,59 a$ & $23,60 \mathrm{a}$ & $69,90 b$ \\
\hline PRepCVeg & $22,66 a$ & $25,85 \mathrm{a}$ & $11,73 a$ & $37,03 \mathrm{a}$ & $22,15 b$ & $71,10 \mathrm{~b}$ \\
\hline Média & 19,38 & 24,42 & 9,28 & 34,73 & 23,13 & 72,86 \\
\hline p-value & 0,0231 & 0,0001 & 0,0121 & 0,0082 & 0,4222 & 0,0085 \\
\hline \multirow[t]{2}{*}{ CV (\%) } & 22,84 & 3,37 & 15,59 & 8,00 & 8,05 & 2,92 \\
\hline & \multicolumn{6}{|c|}{ Silagem } \\
\hline PVegCRep & - & $28,34 a$ & $6,86 c$ & $36,80^{\mathrm{ns}}$ & $19,31 b$ & $71,26^{\mathrm{ns}}$ \\
\hline PRepCRep & - & $28,22 a$ & $6,70 c$ & 40,46 & $23,15 a$ & 68,47 \\
\hline PRepCVegA & - & $23,70 \mathrm{~b}$ & $11,44 a$ & 36,94 & $25,62 a$ & 71,16 \\
\hline PRepCVeg & - & $27,64 a$ & $9,65 b$ & 38,10 & $25,52 a$ & 70,28 \\
\hline Média & - & 26,98 & 8,67 & 38,08 & 23,40 & 70,29 \\
\hline$p$-value & & 0,0001 & 0,0012 & 0,2850 & 0,0011 & 0,2872 \\
\hline CV (\%) & - & 2,96 & 6,82 & 7,33 & 6,94 & 3,04 \\
\hline
\end{tabular}

ns: Não significativo $(\mathrm{p}<0,05)$. *Médias seguidas de mesma letra na coluna não diferem pelo teste de Tukey $(\mathrm{p}<0,05)$. PVegCRep: poda no período vegetativo e colheita no período de repouso fisiológico; PRepCRep: poda e colheita no período de repouso fisiológico; PRepCVegA: poda no período de repouso fisiológico e colheita no período vegetativo antecipado; PRepCVeg: poda no período de repouso fisiológico e colheita no final do período vegetativo.

A composição da parte aérea das plantas coletadas na colheita das raízes também foi significativamente alterada em função dos tratamentos (Tabela 4). A produtividade de massa verde (PMV) foi maior nos tratamentos coletados durante o período vegetativo, colhidos em março e abril, e menor no tratamento em que a poda foi realizada em abril e a colheita em junho. Durante o mês de julho de 2017 houve a ocorrência de geada, que resultou na morte da nova 
brotação que já havia iniciado após a poda, o que pode ter prejudicado o desenvolvimento posterior da parte aérea nas plantas desse tratamento.

A matéria seca foi menor no tratamento com poda no período de repouso fisiológico e colheita no período vegetativo antecipado (PRepCVegA), colhido mais cedo, tanto na forragem fresca quando após a silagem (Tabela 4). A matéria seca tende a aumentar com a idade da planta, pela alteração da relação caule/folha, sendo que brotações mais novas, com mais folhas, tendem a apresentar maior umidade, reduzindo assim os teores (Moreira et al., 2017).

Os teores de massa seca da forragem fresca foram maiores do que os obtidos na época da poda (Tabela 3), porém ambos próximos aos 22 a $25 \%$ relatados em outros estudos (Ferreira et al., 2009; Mota et al., 2011). 0 mesmo foi observado para a matéria seca após a ensilagem, sendo que os materiais das duas épocas apresentam valores de matéria seca condizentes com os citados na literatura, de cerca de $25 \%$ (Modesto et al., 2008; Mota et al., 2011). Embora o material não possua teores próximos aos $30 \%$ e $35 \%$ de matéria seca, o que é recomendando para ensilagens, a prática é recomendada (Modesto et al., 2008).

Assim como observado no material oriundo da poda, aqueles tratamentos coletados durante o período vegetativo (PRepCVegA e PRepCVeg) apresentaram maiores teores de proteína bruta em relação aos demais, na forragem fresca e após a silagem, em função da presença de folhas (Soares et al., 2016). Estes tratamentos também apresentaram maiores teores de FDN e menores teores de NDT, na forragem fresca, em relação ao tratamento que recebeu a poda em abril (PVegCRep). Neste tratamento o intervalo entre poda e colheita foi de 13 meses, superior aos demais, o que permitiu maior desenvolvimento da parte aérea e maior acúmulo de lignina
(Moreira et al., 2017). Após a ensilagem, essa diferença não foi mais observada.

Os valores de proteína bruta obtidos na parte aérea fresca, nas duas épocas coletadas, são semelhantes aos encontrados por Souza et al. (2011), que constataram entre 9,8 e 13,4\% de PB em quatro variedades de mandioca. $\mathrm{Na}$ silagem, os valores estão abaixo dos encontrados em outras pesquisas, onde os valores variaram entre 12 e $20 \%$ (Modesto et al., 2008; Silva et al., 2010; Mota et al., 2011; Marques et al., 2013; Fluck et al., 2017), entretanto todos os valores estão acima dos $7 \%$ considerados mínimos para sustentar o crescimento microbiano e apoiar a digestão eficiente dos ruminantes (Lazzarini et al., 2009).

Os teores de fibra estão baixos comparados com o observado em outros estudos, onde os valores de FDN estavam próximos a 60\% e a FDA em torno de $40 \%$ (Souza et al., 2011; Fernandes et al., 2016). Valores de fibra nessa faixa são considerados elevados (Fluck et al., 2017), e considerando que altos níveis de parede celular diminuem a digestibilidade e limitam o consumo (Azevedo et al., 2006), os baixos teores podem ser vistos de forma benéfica para o uso na alimentação animal.

Segundo o National Research Council (1989), as silagens com excelente valor energético devem apresentar o teor de nutrientes digestíveis totais (NDT) acima de 70\%, geralmente obtidos com a inserção de grãos, sendo que teores abaixo de 60\% indicariam silagem de baixo teor energético. Em todos os tratamentos, nas duas épocas de coleta, os valores ficaram acima de $64 \%$ de NDT, e em alguns inclusive ultrapassaram os $70 \%$, sendo superiores aos relatados na literatura, em torno de 54\% (Azevedo et al., 2006; Silva et al., 2010). Esse resultado indicando que a silagem da parte aérea da mandioca possui boa qualidade energética. 
Sendo assim, nas condições do presente estudo a parte aérea da mandioca cultivar Olho Junto se mostra uma alternativa viável para uso na alimentação animal, tanto na poda do cultivo de dois anos quanto na colheita, apresentando alto valor energético, o que geralmente é um ponto limitante na alimentação animal, e boa composição bromatológica. Entretanto, estudos com diferentes cultivares em clima subtropical se fazem necessários.

\section{Conclusões}

A poda realizada durante o período vegetativo reduz a produtividade de amido, entretanto não altera os demais componentes de rendimento das raízes de mandioca da cultivar "Olho Junto".

A forragem obtida durante 0 período vegetativo, na poda ou na colheita, apresenta maior produtividade e qualidade bromatológica, pela maior relação folha/caule.

\section{Referências}

ANDRADE, J. S.; VIANA, A.E.S.; CARDOSO, A.D.; MATSUMOTO, S.N.; NOVAES, Q.S. de. Épocas de poda em mandioca. Revista Ciência Agronômica, v. 42, n. 3, p. 693701, 2011.

AZEVEDO, E.B.; NÖRNBERG, J.L.; KESSLER, J.D.; BRÜNING, G.; DAVID, D.B.; FALKENBERG, J.R.; CHIELLE, Z.G. Silagem da parte aérea de cultivares de mandioca. Ciência Rural, v. 36, n. 6, p. 1902-1908, 2006.

CAPPELLE, E. R.; VALADARES FILHO, S.C.; SILVA, J.F.C.; CECON, P.R. Estimativas do valor energético a partir de características químicas e bromatológicas dos alimentos. Revista Brasileira de Zootecnia, v. 30, n. 6, p. 1837-1856, 2001.
CQFS - Comissão de Química e Fertilidade do Solo - RS/SC. Manual de calagem e adubação para os Estados do Rio Grande do Sul e de Santa Catarina. 11. ed. Porto Alegre: SBCS, 2016. 375 p.

FERNANDES, F.D.; GUIMARÃES JÚNIOR, R.; VIEIRA, E.A.; FIALHO, J. de F.; MALAQUIAS, J.V. Produtividade e valor nutricional da parte aérea e de raízes tuberosas de oito genótipos de mandioca de indústria. Revista Brasileira de Saúde e Produção Animal, v. 17, n. 1, p. $1-12,2016$.

FERREIRA, A.L.; SILVA, A.F.; PEREIRA, L.G.R.; BRAGA, L.G.T.; MORAES, S.A.; ARAÚJO, G.G.L. Produção e valor nutritivo da parte aérea da mandioca, maniçoba e pornunça. Revista Brasileira de Saúde e Produção Animal, v. 10, n. 1, p. 129-136, 2009.

FLUCK, A.C.; PARZIANELLO, R.R.; MAEDA, E.M.; PIRAN FILHO, F.A.; COSTA, O.A.D.; SIMIONATTO, M. Caracterização química da silagem de rama de cultivares de mandioca com ou sem présecagem. Boletim de Indústria Animal, v. 74, n. 3, p. 176-181, 2017.

IBGE. Instituto Brasileiro de Geografia e Estatística. Produção Agrícola Municipal 2018. Rio de Janeiro, 2019.

LAZZARINI, I.; DETMANN, E.; SAMPAIO, C.B.; PAULINO, M.F.; VALADARES FILHO, S.C.; SOUZA, M.A.; OLIVEIRA, F.A. Dinâmicas de trânsito e degradação da fibra em detergente neutro em bovinos alimentados com forragem tropical de baixa qualidade e compostos nitrogenados. Arquivo Brasileiro de Medicina Veterinária e Zootecnia, v. 61, n. 3, p. 635-647, 2009.

LESSA, L.S.; LEDO, C.A. da S.; SANTOS, V. da S. Effect of harvesting times on agronomic characteristics of industrial 
cassava genotypes. Revista Brasileira de Ciências Agrárias, v. 14, n. 2, p. 1-6, 2019.

MARQUES, K.M.S.; ROCHA JÚNIOR, V.R.; REIS, S.T. dos; SOUZA, V.M. de; PIRES, D.A. de A.; PALMA, N.N. de; SILVA, G.W.V. da. Cinética de fermentação in vitro de silagens da parte aérea de mandioca. Revista Brasileira de Saúde e Produção Animal, v. 14, n. 1, p. 233-247, 2013.

MODESTO, E.C.; SANTOS, G.T. dos; ZAMBOM, M.A.; DAMASCENO, J.C.; BRANCO, A.F.; VILELA, D. Consumo, digestibilidade e parâmetros ruminais em vacas gestantes alimentadas com silagem de rama de mandioca. Revista Brasileira de Zootecnia, v. 37, n. 5, p. 944-950, 2008.

MOREIRA, G.L.P.; VIANA, A.E.S.; CARDOSO A.D.; SANTOS, V. da S.; MASUMOTO, S.N.; ANDRADE, A.C.B. Intervalo entre podas de duas variedades de mandioca. Bioscience Journal, v. 30, n. 6, p. 1757-1767, 2014.

MOREIRA， G.L.P.; PRATES, C.J.N.; OLIVEIRA, L.M.; VIANA, A.E.S.; CARDOSO JÚNIOR, N. dos S.; FIGUEIREDO, M.P. de. Composição bromatológica de mandioca (Manihot esculenta) em função do intervalo entre podas. Revista de Ciências Agrárias, v. 40, n. 1, p. 144-153, 2017.

MOTA, A.D.S.; ROCHA JÚNIOR, V.R.; SOUZA, A.S. de; REIS, S.T. dos; TOMICH, T.R.; CALDEIRA, L.A.; MENEZES, G.C. de C.; COSTA, M.D. da. Perfil de fermentação e perdas na ensilagem de diferentes frações da parte aérea de quatro variedades de mandioca. Revista Brasileira de Zootecnia, v. 40, n. 7, p. 1466-1473, 2011.
NATIONAL RESEARCH COUNCIL. Nutrient requirements of dairy cattle. 6. ed. Washington: National Academy Press, 1989. 157p.

OLIVEIRA, S.P.; VIANA, A.E.S; MATSUMOTO, S.N.; CARDOSO JÚNIOR, N. dos S.; SEDIYAMA, T.; SÃO JOSÉ, A.R. Efeito da poda e de épocas de colheita sobre características agronômicas da mandioca. Acta Scientiarum. Agronomy, v. 32, n. 1, p. 99-108, 2010.

OLIVEIRA, N.T.; ALVES, J.M.A.; UCHÔA, S.C.P.; RODRIGUES, G.S.; MELVILLE, C.C.; ALBUQUERQUE, J. de A.A. de. Caracterização e identificação de clones de mandioca produzidos em Roraima para o consumo in natura. Revista Agro@mbiente On-line, v. 5, n. 3, p. 188-193, 2011.

OLIVEIRA, N.T.; UCHÔA, S.C.P; ALVES, J.M.A.; ALBUQUERQUE, J. de A.A. de; RODRIGUES, G.S. Effect of harvest time and nitrogen doses on cassava root yield and quality. Revista Brasileira de Ciência do Solo, v. 41, p. 1-12, 2017.

PEREIRA, E.S.; PIMENTEL, P.G.; DUARTE, L.S.; MIZUBUTI, I.Y.; ARAÚJO, G.G.L. de; CARNEIRO, M.S. de S.; REGADAS FILHO, J.G.L.; MAIA, I.S.G. Determinação das frações proteicas e de carboidratos e estimativa do valor energético de forrageiras e subprodutos da agroindústria produzidos no Nordeste Brasileiro. Semina: Ciências Agrárias, v. 31, n. 4, p. 1079-1094, 2010.

SENGER, C.C.D.; KOZLOSKI, G.V.; SANCHEZ, L.M.B.; MESQUITA, F.R.; ALVES, T.P.; CASTAGNINO, D.S. Evaluation of autoclave procedures for fibre analysis in forage and concentrate feedstuffs. Animal Feed Science and Technology, v. 146 , n. $1-2$, p. $169-174$, 2008. 
SILVA, C.F.P.G. da; PEDREIRA, M. dos S.; FIGUEIREDO, M.P. de; BERNARDINO, F.S.; FARIAS, D. da H. Qualidade fermentativa e caracterização químicobromatológica de silagens da parte áerea e raízes de mandioca (Manihot esculenta Crantz). Acta Scientiarum - Animal Sciences, v. 32, n. 4, p. 401-408, 2010.

SILVA, D. J; QUEIROZ, A. C. Análise de alimentos: Métodos químicos e biológicos. 3.ed. Viçosa: UFV, 2002. 235 p.

SOARES, I.A.; TÉO, M.S.; DEBASTIANI, C.; RETUCI, V.S.; BARONI, S. Concentrado proteico obtido das folhas de mandioca (Manihot esculenta Crantz) de três variedades comerciais. Acta Ambiental Catarinense, v. 13, n. 1, p. 1-7, 2016.

SOUZA, A.S.; ROCHA JÚNIOR, V.R.; MOTA, A.D.S.; PALMA, M.N.N.; FRANCO, M. de O.; DUTRA, E.S.; SANTOS, C.C.R. dos; AGUIAR, A.C.R. de; OLIVEIRA, C.R. de; ROCHA, W.J.B. Valor nutricional de frações da parte aérea de quatro variedades de mandioca. Revista Brasileira de Saúde e Produção Animal, v. 12, n. 2, p. 441-455, 2011. 